\title{
Mujeres, palta y emociones al margen de las políticas de desarrollo rural en México
}

\author{
Women, avocado, and emotions at the margins of rural \\ development policies in Mexico \\ Mulheres, abacate e emoções à margem das políticas de
desenvolvimento rural no México
}

Alberto Farías Ochoa*

\begin{abstract}
RESUMEN
El presente artículo reporta una etapa de investigación en curso que indaga desde múltiples miradas la condición de la mujer rural del estado de Michoacán, México. Específicamente, la investigación persigue diferentes posibilidades de configuración de la mujer inmersa en la agroindustria de la palta a través de sus luchas, resistencias y resiliencias que se construyen en un contexto adverso marcado por la violencia, la inequidad y la exclusión en espacios reconocidos tradicionalmente por el dominio patriarcal. La etapa metodológica que se presenta es la de un diagnóstico de corte etnográfico que hace énfasis en las emociones de las participantes y la de la constitución de una Comunidad de Práctica y Aprendizaje que propicia la construcción de diálogos emergentes para nombrar la realidad, configurarla y significarla, al tiempo que se avanza en las condiciones inherentes a sus preocupaciones inmediatas. Historias de vida, entrevistas semiestructuradas y grupos de discusión son las técnicas empleadas en la recolección de las experiencias. Como resultados parciales se tiene un llamado urgente para la transformación de las políticas públicas que han omitido históricamente las condiciones de la mujer rural en el campo mexicano.
\end{abstract}

Palabras clave: mujeres rurales, producción de palta, resistencias femeninas.

\footnotetext{
* Mexicano. Doctor en Educación con orientación en Tecnologías de la Información. Coordinador de la Licenciatura en Comunicación de la Universidad Michoacana de San Nicolás de Hidalgo. Miembro de la Asociación Mexicana de Investigadores de la Comunicación. Morelia, México. alberto.farias@umich.mx
} 


\begin{abstract}
This article reports a stage of ongoing research that investigates from multiple perspectives the condition of rural women in the state of Michoacán, Mexico. Specifically, the research pursues different possibilities for the configuration of women immersed in the avocado agroindustry through their struggles, resistance, and resilience built in an adverse context marked by violence, inequity, and exclusion in spaces traditionally recognized patriarchal dominance. The methodological stage presented is an ethnographic diagnosis that emphasizes participants' emotions and the constitution of a Community of Practice and Learning that favors the construction of emergent dialogues to name reality, configure it, and signify it while advancing in the conditions inherent to their immediate concerns. Life histories, semistructured interviews, and discussion groups are the techniques used in the collection of experiences. As partial results, there is an urgent call for the transformation of public policies that have historically omitted the conditions of rural women in the Mexican countryside.
\end{abstract}

\section{RESUMO}

Este artigo relata uma etapa da pesquisa em curso que indaga desde múltiplas perspectivas a condição da mulher rural do estado de Michoacán, no México. Especificamente, a pesquisa aborda diferentes possibilidades de configuração da mulher imersa na agroindústria do abacate através de suas lutas, resistências e resiliências construídas em um contexto adverso marcado pela violência, desigualdade e exclusão em espaços reconhecidos tradicionalmente pelo domínio patriarcal. A etapa metodológica apresentada é a de um diagnóstico de corte etnográfico cuja ênfase está nas emoções das participantes e na constituição de uma Comunidade de Prática e Aprendizagem que propicia a construção de diálogos emergentes para nomear a realidade, configurá-la e dar-lhe significado, enquanto se avança em condições inerentes a suas preocupações imediatas. Histórias de vida, entrevistas semiestruturadas e grupos de discussão são as técnicas empregadas na coleta das experiências. Como resultados parciais, obtém-se um chamado urgente para a transformação das políticas públicas que omitiram historicamente as condições da mulher rural no campo mexicano.
Keywords: rural women, avocado production, women's resistance.

Palavras-chave: mulheres rurais, produção de abacate, resistências femininas. 


\section{Condiciones contextuales del estudio}

El estudio que se reporta en este trabajo describe las condiciones de la agroindustria de la palta (aguacate, como se le nombra en México y Centroamérica) en el estado de Michoacán, México. Concretamente, aporta una mirada prácticamente inexistente en los antecedentes de estudio: el papel de la mujer pequeño productora de palta y las adversidades que enfrenta ante su dinámica de vida inmersa en una cadena de valor, en donde pareciera no tener cabida, pero en la que sí se hace presente a través de diversas modalidades y condiciones mayoritariamente adversas para sus intereses y garantías como ciudadana.

El estado de Michoacán, México, es reconocido como el primer productor de palta en el mundo, y el enaltecimiento de esta agroindustria por parte de gobernantes de diferentes niveles, así como por los grandes consorcios de comercio internacional ha sido una constante en las últimas tres décadas. En este periodo la producción de la palta se ha potenciado a niveles exponenciales tales, que cada vez es un negocio más atractivo para inversionistas locales y extranjeros. Las condiciones tropicales y de humedad del campo mexicano, aunadas a su posición geográfica respecto de Estados Unidos de América — primer país importador de palta en el mundo-, se suma la reciente apertura de los mercados asiáticos para la exportación de frutas tropicales provenientes de América Latina, todo lo cual ha generado una demanda en crecimiento constante que hace a la palta una mercancía clave para el crecimiento económico de México y más específicamente del estado de Michoacán.

En materia de la demanda de esta fruta tropical, la Organización de las Naciones Unidas para la Agricultura y la Alimentación (FAO) y la Organización para la Cooperación y el Desarrollo Económicos (OCDE) estiman que América Latina mantendrá un alza constante en la demanda de este producto, de modo que en la región se pueden superar los 12 millones de toneladas exportadas al año (OCDE-FAO, 2019). $\mathrm{Al}$ respecto, Arias y Arboleda (2018) destacan que $77 \%$ de la palta que se importa en el mundo proviene de Latinoamérica, identificándose como principales países importadores Estados Unidos, Francia y los Países Bajos. Complementariamente, la apertura del mercado asiático marca un hito importante para la dinámica del preciado producto agrícola, ya que debido al reconocimiento de sus propiedades se le ha 
integrado a la dieta cotidiana en varios países principalmente de Asia Pacífico. Caballero et al. (2015) ya advertían que siendo un alimento con grandes cualidades nutricionales, rico en fibra, proteína, vitaminas, antioxidantes y minerales, su demanda en el mundo se incrementaría a razón de superar la oferta, lo que de manera natural implicaría una serie de especulaciones con impacto directo en su precio y en el comercio internacional. Cabe señalar en este sentido que:

El proceso de expansión de la producción de aguacate resulta emblemático de la experiencia neoliberal mexicana por las siguientes razones: expresa los cambios derivados de una apertura comercial brusca; implica la reconversión productiva del campo impulsada por el Estado en perjuicio de la producción de granos básicos y a favor de los cultivos de exportación; se caracteriza por la creciente explotación de los bienes naturales y un acelerado crecimiento de la frontera agrícola reflejada en los extensos monocultivos; finalmente desplaza o subordina a la producción campesina y a la propiedad social para favorecer la progresiva participación de la agroindustria y a los grandes productores. (Toribio et al., 2019, p. 52).

En el caso del estado de Michoacán, la localidad reconocida como principal productora de palta en México y también en el mundo, solamente en el año 2017 se estimó su producción en 1.674.855 toneladas, lo que representa más del 75\% de la producción de todo el país de acuerdo con datos referidos por el Centro de Estudios para el Desarrollo Rural Sustentable y la Soberanía Alimentaria (2017). Dicha entidad calcula que el incremento del cultivo de palta en el estado de Michoacán ha sido desproporcionado y poco ordenado, pasando de un promedio de 31 mil hectáreas sembradas en 1980 a 166.604 en el año 2017, y siguen incrementándose.

Además del crecimiento constante de la agroindustria de la palta en México, crecen también problemáticas relacionadas con conflictos de inequidad social, de crisis ecológicas, de desigualdades económicas y de violencia perpetrada en diferentes modalidades. Al margen de estos señalamientos, las denuncias más conocidas son las identificadas con los crímenes ecológicos como la tala clandestina de los bosques y el agotamiento de mantos acuíferos, entre otros. El conflicto ha tomado dimensiones críticas derivando incluso en conflictos armados en defensa de los bosques y en el reclamo constante a los gobernantes 
para aplicar la legislación vigente en materia de la preservación de los recursos naturales que son patrimonio de los habitantes de la zona, muchas veces comunidades indígenas en riesgo de la pérdida de sus patrimonios comunales.

De acuerdo con Maldonado (2019), las tensiones agrarias entre las habitantes de comunidades indígenas y empresarios agrícolas particulares se han incrementado en los últimos años ante la expansión de las colindancias de los predios particulares y las tierras comunales, lo cual ha generado que las transgresiones de los empresarios aguacateros sean parte ya de la agenda prioritaria de las llamadas guardias comunitarias como las de Cherato y Cherán ${ }^{1}$, por poner un ejemplo. A decir de Padgett en Casparello (2018) las redes de comercialización del aguacate son también parte importante de la economía criminal. En efecto, mediante actividades como el cobro de cuotas a productores, extorsiones para el acceso a la comercialización e incluso limitaciones para la gestión de permisos ante los gobernantes en turno, el crimen organizado se ha posicionado en el atractivo sistema de producción de la palta para dar legitimidad a diversas actividades ilícitas.

A pesar de que las condiciones de inequidad, violencia y polarización social son múltiples en su relación con la agroindustria de la palta, esta investigación pone énfasis en las condiciones de las mujeres que se encuentran inmersas en esta práctica agrícola; mujeres que no han sido beneficiadas por las políticas públicas de apoyo al campo y que sí comparten los recursos naturales de su entorno, que se integran a la dinámica laboral del campo y que ponen en riesgo su salud y las de sus familias. Específicamente, se hace referencia a las mujeres que, debido a la dinámica de su comunidad inmersa en la cadena de comercio de la palta, han tenido que incorporarse a dicho cultivo a través de la disposición de sus tierras como pequeñas propietarias en un sentido de supervivencia y resiliencia, más que de desarrollo empresarial.

Son comunes los casos de familias productoras del campo en las que, mientras los varones se agregan como jornaleros a los grandes consorcios agrícolas, las mujeres se quedan en la pequeña propiedad para cuidar y trabajar los árboles de palta que han dispuesto en su

1 Pueblos indígenas ubicados en la llamada Meseta Purépecha de Michoacán, México. 
propio huerto (casi nunca superando las tres hectáreas) otorgándoles tiempo, recursos, cuidados múltiples y aprendizajes empíricos a una cadena de valor establecida por las grandes empacadoras con rutas de exportación. Así, una realidad cotidiana es la de la inequidad ante el logro de las cosechas, ya que al ser pequeñas propietarias su cosecha no es atractiva para las empacadoras, quienes les ofrecen pagos muy por debajo del mercado, lo que les genera un déficit en la inversión de las pequeñas productoras. Otra posibilidad es la de colocar la cosecha en los mercados locales, sin embargo, al encontrarse en una región saturada por la misma mercancía, nuevamente esta opción les genera un déficit de su inversión. Dicha condición de inequidad es producto de una omisión histórica de la mujer rural en las políticas públicas de fomento del campo, específicamente las relacionadas con el cultivo de palta.

En este orden de ideas, y desde una mirada multidisciplinaria del fenómeno en el que se revisa el aspecto económico, las posibilidades del desarrollo regional, las condiciones del desarrollo sustentable y otros, este reporte de investigación aporta un análisis de la experiencia de la mujer productora, en la que desde su propio relato se le construye sentido a la experiencia y se da nombre a las emociones para dotar de significado su mundo. A través de una Comunidad de Práctica y Aprendizaje orientada a las alternativas de mercado para la colocación de sus mercancías, un grupo de mujeres participa en la construcción de diálogos que dan oportunidad de dimensionar sus emociones, preocupaciones e intereses en el marco de una coyuntura permanente, pero que además ha sido matizada por particularidades muy específicas relacionadas con la pandemia COVID-19.

\section{Perspectiva teórica del estudio}

La investigación se sustenta - para la comprensión de la realidad a través de las propias experiencias de las mujeres productoras de palta-, en un marco teórico analítico de la Ecología Política Feminista, el cual revisa las políticas públicas orientadas a las mujeres rurales, así como las condiciones de violencia, discriminación y otras adversidades a las que se enfrenta este sector desde la práctica de un dominio patriarcal para el desarrollo de su vida en bienestar. Así, por ecología política feminista se comprende ese cuestionamiento de las relaciones de género 
y el medio ambiente en sus diferentes formas de desarrollo y de resistencia.

$\mathrm{Al}$ respecto, se coincide con la idea de que la tradición de la ecología política feminista adopta:

una postura crítica hacia la apertura de nuevas temáticas de debate sobre la relación género-medio ambiente, tales como la construcción social de género mediadas en y a través de materialidades ecológicas, la visibilización de (otras) formas de conocimiento desde una mirada decolonial o bien la profundización de la idea de interseccionalidad. (Arriagada y Zambra, 2019, p. 14).

La ecología política feminista implica, de suyo, una idea decolonizadora de la dinámica social, en donde la reflexión se demanda como una constante y los cuestionamientos son una práctica permanente, los cuales permiten la definición de los objetivos de la cotidianidad desde las necesidades de las protagonistas y no desde los postulados axiomáticos dictados por la tradición patriarcal. Esta mirada implica una postura epistemológica que se pregunta el por qué y el para qué de la construcción de conocimientos y la transmisión de saberes. Así, de acuerdo con Vázquez (2020), la ecología política feminista permite problematizar la construcción de conocimientos y axiomas arraigados en comunidades complejas y propone, a la vez, alternativas innovadoras para decolonizar paulatinamente los saberes a favor de las mujeres inmersas en una realidad de adversidades.

Como referente de las políticas públicas para la mujer en el entorno rural de México se reconoce una profunda crisis de omisión, en el sentido de la existencia de políticas públicas encaminadas en beneficio de la mujer en la dimensión de la normativa oficialista y burocrática del Estado desde hace más de tres décadas, pero con condiciones desvinculadas de la realidad, de las necesidades y exigencias con base en la diversidad de las mujeres rurales. En continuidad con lo anterior,

Las políticas neoliberales [en México] agudizaron la desigualdad en el campo, se benefició la agroexportación con programas de fomento productivo, mientras los apoyos para pequeños productores buscaron paliar los efectos negativos de la apertura comercial y la competencia con presupuestos marginales. (Soto, 2019, p. 172). 
En este sentido, se presume que las políticas públicas de carácter macroeconómico apostaron por la riqueza del país, perdiendo de vista las condiciones de distribución y de crecimiento equitativo para las productoras del entorno rural. Adicionalmente, se tiene que los diferentes programas de desarrollo fueron diseñados por actores ajenos al campo de aplicación en un marco de desconocimiento de las condiciones de la mujer rural, agudizando así las asimetrías en relaciones de género que ya suponían una crisis histórica en este sector demográfico.

Al tiempo de acusar una distribución inequitativa de los programas de desarrollo agropecuario en el campo mexicano, se reflexiona acerca del papel de la pequeña agricultura familiar como medida de crecimiento económico para la mujer rural, ya que al no ser considerada en las condiciones de industrialización de la agricultura, la mujer campesina contribuye a los modelos microeconómicos de manera permanente en la dinámica de su vida cotidiana, aun cuando esta cotidianidad está caracterizada por las condiciones de inequidad, de injusticia y muchas veces de violencia. De acuerdo con Robles (2016), la pequeña agricultura campesina es una modalidad de producción y supervivencia para las familias del entorno rural no favorecidas por la política pública de desarrollo agropecuario, la que ha crecido en México en los últimos 80 años producto de una orientación hacia la riqueza macroeconómica del país que omite a las pequeñas productoras familiares.

En este conjunto de ideas se tiene que la mujer agricultora se inserta en las agroindustrias de su entorno como medida de supervivencia para ella y para su familia, al tiempo que pugna por las condiciones de la conservación de sus recursos naturales en los que se desarrolla su familia, recursos naturales que son botín de una depredación desproporcionada por parte de los grandes inversionistas con mirada colonizadora de las comunidades, y que genera condiciones de adversidad para las habitantes de la zona, muchas veces detonando severos escenarios de violencia por la defensa de la tierra y el derecho a la vida digna.

En concordancia con posturas como las de Nightingale (2006), en esta investigación se considera preponderante la problematización permanente de las relaciones de género y medio ambiente en las que 
la conceptualización de los derechos de la participación, la propiedad y las lógicas simbólicas se orienten hacia una dinámica equitativa, pero también respetuosa de las diferentes formas de vida en el entorno. El género, y sus condiciones de pugna son un eje conductor de las discusiones con las que se aprecia la realidad de las mujeres productoras familiares de la palta en Michoacán, para comprender nuevas aristas que parecen ser todavía omitidas en las luchas socioecológicas de nuestros tiempos.

En relación con este marco de referencia teórica, se tiene que el trabajo con las mujeres participantes en este estudio se integró con mujeres que entre sus quehaceres cotidianos refirieron trabajar los árboles de palta propios o familiares. Históricamente, así como lo reporta Herrera (2017) las mujeres solían agregarse a la cadena de producción de la palta en la manufactura de cajas contenedores para el transporte de la fruta, sin embargo, esta práctica quedó relegada ante la incorporación de contenedores de plástico que se introdujeron como medida de ahorro por parte de los propios empresarios, por lo que el papel de la mujer en esta agroindustria parecía haber desaparecido. Así, esta investigación pone énfasis en mujeres que sí están trabajando la producción de palta, pero no necesariamente bajo el sistema de contrato de algún empresario, es decir, se privilegia a mujeres que por condiciones familiares son propietarias de plantaciones de palta en baja escala.

\section{Características metodológicas del trabajo con mujeres productoras de palta}

La caracterización de las participantes en el estudio se situó en la comunidad de Atécuaro Michoacán, México, y consistió en una convocatoria para la capacitación en la elaboración de productos derivados de palta a través del procesamiento y su conformación en productos que ya cuentan con demanda en mercados alternativos tales como la extracción de aceite, la elaboración de cosméticos y la elaboración de conservas. 
Figura 1.

Estado de Michoacán, y localidad del estudio

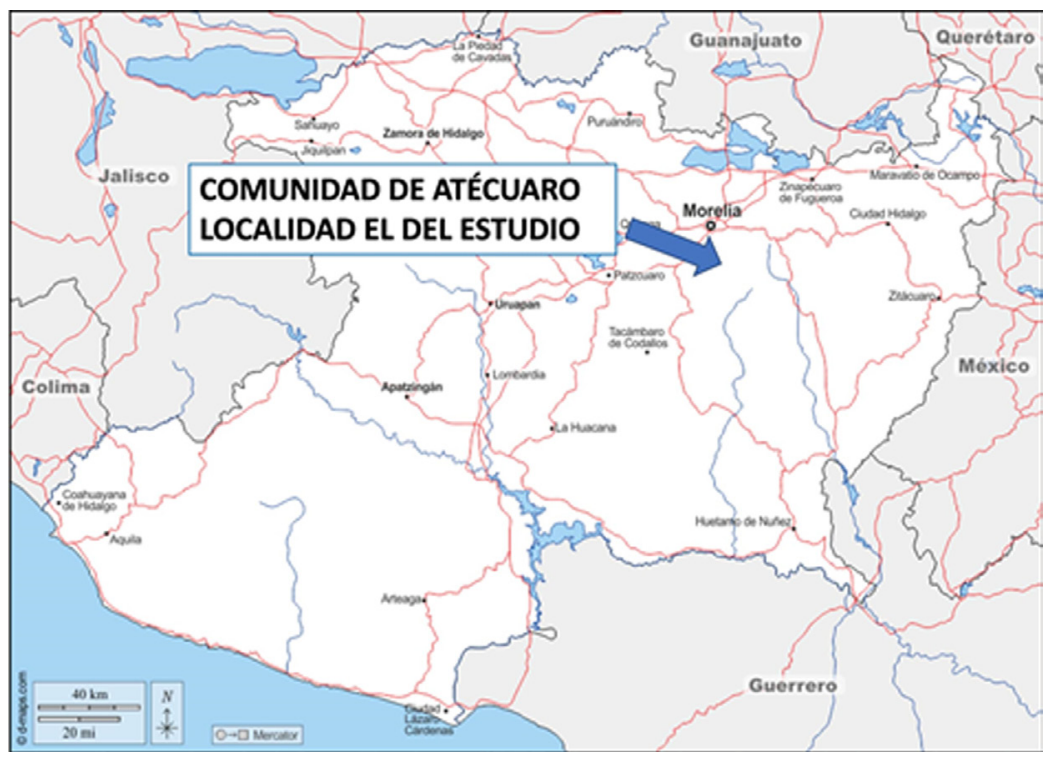

Fuente: Elaboración propia.

La convocatoria de capacitación fue gestionada por una estudiante de posgrado en Desarrollo Regional de la Universidad Michoacana de San Nicolás de Hidalgo, en conjunto con una estudiante del posgrado de Bioquímica en Alimentos del Instituto Tecnológico de Morelia. La intención de la convocatoria en términos genéricos fue la de otorgar capacitación a las mujeres involucradas para evitar el desperdicio de sus cosechas y dotarlas de procesos para su colocación en mercados alternativos relacionados con la palta. No obstante, la dinámica de la capacitación no se ofreció de manera instruccional clásica, sino que se conformó una Comunidad de Práctica y Aprendizaje (en adelante $\mathrm{CPA}$ ) en la que el conocimiento y la experiencia de cada una de las participantes en diferentes áreas de la vida fue una fortaleza latente del conjunto, pero además fue lo que propició la dinámica del diálogo problematizador entre iguales.

Para esta investigación se concibe la CPA de acuerdo con Farías (2020), como ese conjunto de personas que comparte interés por el dominio de algún conocimiento específico y que, a través de los vínculos creados entre ellos, configuran nuevas indagatorias que abonan a la 
estructura de sus aprendizajes relacionados con su cotidianidad. Así, el fin no se centra en la adquisición de competencias técnicas, sino que se fomenta un ciclo de enseñanzas y apropiaciones de conocimientos múltiples que toman diferentes direcciones, y que a través de un flujo de aportaciones multicéntricas y heterárquicas ${ }^{2}$ ( en las que no se privilegian las jerarquías y los mensajes fluyen libremente entre todas las participantes) dan vida a la CPA con las constantes significaciones que le otorgan a sus discusiones.

La CPA fue una modalidad propicia para este estudio en el entendido de que se identificó la esencia de los cuatro aspectos indispensables de comunidad en los términos de básicos de Wenger y Sánchez (2001), y son:

- El significado: una manera de hablar de nuestra capacidad (cambiante) -en el plano individual y colectivo-, de experimentar nuestra vida y el mundo como algo significativo.

- La práctica: una manera de hablar de los recursos históricos y sociales, los marcos de referencia y las perspectivas compartidas que pueden sustentar el compromiso mutuo en la acción.

- La comunidad: manera de hablar de las configuraciones sociales donde la persecución de nuestras empresas se define como valiosa, y nuestra participación es reconocible como competencia.

- La identidad: una manera de hablar del cambio que produce el aprendizaje de quiénes somos y de cómo crea historias personales en el devenir en el contexto de nuestras comunidades (Wenger y Sánchez, 2001).

El objetivo principal de la CPA fue en todo momento el de generar diálogos problematizadores que permitieran disponer de la información, nombrarla, cuestionarla, intercambiarla, deconstruirla y dotar de nuevos significados a sus emociones, acorde con sus necesidades, resistencias e intereses. El hilo conductor de la CPA fue el de la capacitación en procesos de la palta para la apertura de nuevos mercados, sin embargo, la dinámica de la gestión del grupo apuntó hacia la materialización de las experiencias para revisar de

2 Se dice que una comunicación es multicéntrica y heterárquica cuando no tiene base en la jerarquía, y la agenda de las discusiones surge de manera dinámica desde cualquiera de los nodos de las participantes de manera espontánea otorgándole el mismo nivel de importancia a cualquiera de las discusiones expuestas. 
manera alternativa las acciones protagónicas de las mujeres rurales como agentes de resiliencia, y no solamente de supervivencia, ante las condiciones poco favorables de un mundo patriarcal profundamente inequitativo en el ámbito de las políticas públicas orientadas al campo mexicano.

\section{Recolección de la información a través de la comunidad de práctica}

La estrategia de cobertura más efectiva para la conformación de la comunidad de práctica, y de acuerdo con las condiciones de comportamiento de conglomerados en las zonas rurales, fue la llamada bola de nieve que, en congruencia con las bondades que describe Galindo (1998) acerca de esta técnica, permitió que una mujer refiriera a otra con las mismas características y con posibilidades de interés en la participación.

Mediante una mirada etnográfica, en el inicio de los trabajos de campo se estableció que las participantes relataran su dinámica cotidiana de vida. A través de un diario de campo (Díaz, 2011) se consignaron ciertas condiciones y problemáticas a las que las mujeres se enfrentan día a día para darles registro, sistematización y sentido en función de las indagatorias. En esta etapa de la investigación se tuvo oportunidad de incorporar el relato de las participantes en su calidad de coinvestigadoras, ya que al propiciar el sentir de su realidad señalaban al mismo tiempo nuevas rutas de exploración que, de manera original, no habían sido planteadas por la investigación. En este sentido, destacaron las condiciones de conocimiento que tienen las mujeres de su entorno, el reconocimiento de ciclos de impacto y mitigación propiciados por el cambio climático y los escenarios de inequidad a los que se enfrentan derivados de su propia condición de mujer.

La propuesta de las temáticas a tratar en la CPA se distribuyó acorde con los ejes técnicos de interés, así se estructuraron cuatro módulos: fisiología de la palta; extracción de aceite de palta; elaboración de cosméticos con base en palta; y, elaboración de conservas de palta. Toda la etapa técnica fue supervisada, ejecutada y monitoreada por las estudiantes de posgrado de Desarrollo Económico y de Bioquímica en Alimentos. 
A partir de la etapa de la convocatoria y durante el registro de las notas de campo se incorporó como coinvestigadora una profesora de Educación Básica residente de la misma zona, quien también asumió un papel de participante en la capacitación y que tenía reconocimiento previo de liderazgo con las mujeres de la zona. La contribución adicional de dicha docente fue también la de motivar temas de discusión, registrar las experiencias en materiales audiovisuales y hacer apuntes clave in situ, todas las anteriores con ejes discursivos acordes con los propósitos de la investigación. La participación de la profesora en calidad de motivadora de discusiones clave y de recolectora de los datos para el análisis fue remunerada por parte de la investigación, al mismo tiempo, las mujeres participantes estuvieron notificadas de la labor de dicha participante y de la intención del trabajo de los materiales registrados, garantizando la debida protección de datos confidenciales de acuerdo con la Ley Federal de Datos Personales en Posesión de los Particulares (vigente en México).

Los aspectos más relevantes de la dinámica de trabajo con las participantes fueron mediados a través del lenguaje que permitía materializar las formas de apreciar el mundo, así como, paulatinamente, darle nombre a los sentimientos que algunas realidades generan en las mujeres rurales participantes. En el marco de este intercambio constante de diálogos problematizadores surgieron categorías muy bien identificadas que eran parte de la orientación de las nuevas discusiones, y que retroalimentaron la cohesión de la comunidad.

Como se decía, el lenguaje fue un factor clave debido a que permitió compartir información desde las diferentes áreas de experiencia de las participantes, pero también propició la reflexión, el cuestionamiento de símbolos y la negociación constante de significados, lo que a la vez dio evidencia de la apropiación paulatina de las categorías en discusión. El posicionamiento epistemológico y ontológico de la intervención marcó en todo momento como prioridad a la mujer como negociadora de sus preocupaciones, en contraste con su propio entorno y con la posibilidad de considerar a sus pares como agentes clave para el cuestionamiento de su realidad, una realidad que no se limitó a solucionar el problema económico mercantil de las preocupaciones iniciales, sino que permitió cuestionar las estructuras históricas que han llevado el papel de la mujer rural a las condiciones de inequidad que se enfrentan el día de hoy. 
Para el abordaje de los contenidos de los cursos técnicos acerca del procesamiento de la palta y la apertura de nuevos mercados, se generó un promedio de dos sesiones por semana regularmente por las tardes de los días viernes y sábado. $\mathrm{Al}$ respecto, se eligieron esos días de la semana ya que las mujeres participantes reconocían disposición de agenda ante sus múltiples responsabilidades como mujeres de familia, a las que se les adherían labores del hogar, de cuidados, de administración familiar, de acompañamiento en el aprendizaje escolarizado de los hijos y de otras tantas que se asumen como responsabilidad de la mujer desde esta mirada todavía patriarcal e inequitativa.

En este contexto se desarrolló un total de 42 sesiones que inicialmente se diseñaron para ser trabajadas en el periodo comprendido entre los meses de marzo y junio del año 2020. Sin embargo, dadas las medidas de confinamiento promovidas por las autoridades mexicanas a partir del mes de abril derivadas de la pandemia COVID-19, aunado al posicionamiento de las instituciones educativas para la disposición de sus voluntarias en el trabajo de campo, las sesiones culminaron hasta el mes de diciembre de 2020. Más allá de haber dilatado el tiempo de trabajo para la CPA por motivos de la pandemia, dicha circunstancia tuvo un resultado fortuito para la investigación debido a que permitió incorporar una arista por demás importante en la dinámica de la comunidad: la incorporación tecnológica como mediadora de las posibilidades de discusión.

Al tiempo de la comunidad de práctica, la participante motivadora de las discusiones también realizó varias entrevistas semiestructuradas a cada una de las participantes, lo que permitió contrastar permanentemente las iniciativas de los diálogos con la aparición de nuevas categorías de discusión, y dar idea de la configuración de las emociones inmediatas que las participantes manifestaron en las diferentes etapas, además de que dichas entrevistas se convirtieron más tarde en una herramienta para la validación de los resultados mediante un ejercicio de contraste en cada caso particular. Aunado a lo anterior, también se dio lugar a la conformación de autobiografías que dieron oportunidad de apreciar ciertas características en cada una de las participantes, lo que reforzó el interés y las preocupaciones en común por parte de la comunidad de práctica y aprendizaje. 
Los materiales recopilados producto de entrevistas, narrativas autobiográficas y grupos de discusión fueron respaldados de manera digital para su inmediata sistematización, ordenamiento y análisis para la indagatoria de inferencias preliminares y la toma de decisiones en laboratorio. En este sentido, la condición de trabajo paralelo de las actividades de recopilación y de sistematización permitieron el avance en la transcripción de los diálogos y narrativas, que fueron la materia prima con la que se estableció la búsqueda de categorías analíticas a través de las enunciaciones y las formas de nombrar la realidad por parte de las mujeres rurales participantes.

El acervo léxico y la identificación de las formas de enunciación se convirtieron en una clave para la identificación de los ejes nodales de manifestación de las preocupaciones e intereses de las mujeres participantes. La forma de enunciar la realidad otorgó sentido a las condiciones simbólicas de hechos y sucesos de los cuales las mujeres se sienten parte protagónica, pero en los que se reconocen en desigualdad a través de gran cantidad de prácticas cotidianas que pocas veces se han detenido a reflexionar. Las temáticas socializadas identificadas a través de los registros de las entrevistas y de las discusiones permitieron explorar una gran variedad de tópicos que se mueven en dimensiones de intimidad distintas: los hay aquellos que tienen que ver con problemáticas comunes al interior del hogar y aquellos que incluso generan polémica por las decisiones de los gobernantes en turno.

La disposición de las transcripciones de las discusiones permitió apreciar también las variables de liderazgos itinerantes dependientes de la temática a discutir. En la mayoría de los casos se identificó un área de experiencia que se le reconocía a cada una de estas mujeres por parte de las otras mujeres también participantes, con exposiciones de experiencia que iban desde el dominio en las labores de cocina, así como por sus habilidades como gestoras de apoyos ante los diferentes programas de gobierno. Los liderazgos identificados - en contraste con las autobiografías desarrolladas por las propias mujeres- permitió, a la vez, construir un rango de congruencia en cuanto a las potencialidades de cada una de las participantes para tocar otras temáticas complementarias de interés para la investigación, como las de construcción de ciudadanía, la participación política, el feminismos y otras. 
Durante los trabajos de la CPA se obtuvo un porcentaje de retención de las participantes del 75\%, ya que solamente lograron permanecer hasta la última etapa ocho de las 12 mujeres iniciales, y son de estas ocho mujeres de quienes se comparten los resultados en el siguiente apartado.

\section{Sistematización de la información y análisis de categorías}

Los materiales recopilados para el análisis en los registros a través de las transcripciones merecieron un tratamiento multimodal para identificar líneas temáticas competentes con los objetivos de la investigación. Así, se identificaron marcadores discursivos, funciones de la enunciación, modos y empleo de metáforas y estilos de relatos autobiográficos. Todos los anteriores permitieron realizar un tejido de ideas que apuntó hacia el interés general de la investigación. A manera de referencia, se presentan a continuación tres tablas que dan idea de la transformación de las discusiones en símbolos empleados por las mujeres participantes para enunciar su mundo y sus emociones.

La dinámica de ordenamiento de la Tabla 1 consistió en identificar la temática técnica con el procesamiento de la palta que se impartió por parte de las capacitadoras expertas en cada módulo para, de manera paralela, registrar las conversaciones derivadas en la retroalimentación y relacionarlas con conceptos que se hicieran presentes de manera recurrente en los diálogos. Una vez identificados estos conceptos se etiquetaron como una categoría clave para la investigación.

Tabla 1

Ejes discursivos y categorías de atención

\begin{tabular}{llll}
\hline Temática técnica & Fragmentos conversacionales & $\begin{array}{l}\text { Funciones de la } \\
\text { enunciación }\end{array}$ & $\begin{array}{l}\text { Categoría } \\
\text { identificada }\end{array}$ \\
\hline $\begin{array}{l}\text { Condiciones del } \\
\text { mercado de la } \\
\text { palta. }\end{array}$ & $\begin{array}{l}\text { ¿O sea que cuando usted dice mercados, } \\
\text { quiere decir lugares para vender? } \\
\text { ¿O sea que no nomás se vende a las empa- } \\
\text { cadoras y a la gente de a pie? }\end{array}$ & $\begin{array}{l}\text { De declaratoria de } \\
\text { desconocimiento. }\end{array}$ & Inequidad. \\
\hline $\begin{array}{l}\text { Oportunidades } \\
\text { de mercado- }\end{array}$ & $\begin{array}{l}\text { Para que me den tres pesos por caja, me- } \\
\text { jor que se desperdicie y se lo traguen los }\end{array}$ & $\begin{array}{l}\text { De denuncia de } \\
\text { inconformidad. }\end{array}$ \\
\hline $\begin{array}{l}\text { Crecimiento de } \\
\text { oportunidades } \\
\text { para exporta- }\end{array}$ & $\begin{array}{l}\text { Eso que usted dice maestra estaría bien si } \\
\text { yo tuviera 20 hectáreas y 40 peones, pero } \\
\text { ción. }\end{array}$ & $\begin{array}{l}\text { yo, mis hijas y mis manos no estamos para } \\
\text { esos aires. }\end{array}$ & $\begin{array}{l}\text { posición de des- } \\
\text { ventaja. }\end{array}$ \\
\hline
\end{tabular}




\begin{tabular}{|c|c|c|c|}
\hline $\begin{array}{l}\text { Optimización de } \\
\text { las cosechas. }\end{array}$ & $\begin{array}{l}\text { Nosotros una vez síle pagamos a un disque } \\
\text { ingeniero que nos iba a decir cómo hacerle, } \\
\text { pero bien caro que cobró y al final tuvimos } \\
\text { la misma cosecha roñosa de siempre. }\end{array}$ & $\begin{array}{l}\text { De declaratoria de } \\
\text { no credibilidad en } \\
\text { la tecnificación. }\end{array}$ & \\
\hline $\begin{array}{l}\text { Desarrollo } \\
\text { sustentable y } \\
\text { sostenible. }\end{array}$ & $\begin{array}{l}\text { Yo sí trato de no echarle químicos a las } \\
\text { matas, porque luego andan los chiquillos } \\
\text { jugando ahi, y es bien peligrosa esa cosa. } \\
\text { Pero hubiera de ver allá arriba en las huertas } \\
\text { de Don -------, pomos y pomos de agro- } \\
\text { químico que le echan a esos aguacates, total, } \\
\text { como no son sus hijos los que trabajan ahí. }\end{array}$ & $\begin{array}{l}\text { De denuncia de } \\
\text { no respeto por las } \\
\text { normas vigentes. }\end{array}$ & \multirow[t]{2}{*}{ Inequidad. } \\
\hline $\begin{array}{l}\text { Prácticas de } \\
\text { inocuidad en } \\
\text { procesos. }\end{array}$ & $\begin{array}{l}\text { Es que para eso pues se necesitan estudios, } \\
\text { y luego también armar una fabriquita para } \\
\text { cuidar todo eso, mi marido trabajó para } \\
\text { una empacadora y dice que sí es una joda. }\end{array}$ & $\begin{array}{l}\text { De declaratoria de } \\
\text { posición de des- } \\
\text { ventaja. }\end{array}$ & \\
\hline $\begin{array}{l}\text { Participación en } \\
\text { ferias y capacita- } \\
\text { ciones. }\end{array}$ & $\begin{array}{l}\text { A nosotros sí nos invitaron a una feria en } \\
\text { Morelia, pero mi marido dijo que era mu- } \\
\text { cha lata y que ni se le sacaba mucho. }\end{array}$ & $\begin{array}{l}\text { De reconocimiento } \\
\text { de limitantes. }\end{array}$ & \multirow[t]{4}{*}{ Patriarcado. } \\
\hline $\begin{array}{l}\text { Conocimientos } \\
\text { de biología } \\
\text { básica. }\end{array}$ & $\begin{array}{l}\text { Cuando iba a la secundaria una maestra } \\
\text { sí nos hablaba de las plantas y las flores } \\
\text { y todo eso, y sí me gustaba, pero yo no } \\
\text { terminé porque me sacaron cuando mi } \\
\text { mamá se embarazó del más chiquillo de } \\
\text { mis hermanos. }\end{array}$ & $\begin{array}{l}\text { De evidencia de la } \\
\text { falta de oportuni- } \\
\text { dades. }\end{array}$ & \\
\hline $\begin{array}{l}\text { Administración } \\
\text { del sistema de } \\
\text { cosechas. }\end{array}$ & $\begin{array}{l}\text { A mí mi marido nomás me dice cuánto } \\
\text { salió y cuánto compré de cada cosa que se } \\
\text { ocupa, yo pago todo con lo que él me da. }\end{array}$ & $\begin{array}{l}\text { De evidencia de } \\
\text { limitaciones en } \\
\text { la toma de deci- } \\
\text { siones. }\end{array}$ & \\
\hline $\begin{array}{l}\text { Cooperativas de } \\
\text { mujeres produc- } \\
\text { toras. }\end{array}$ & $\begin{array}{l}\text { Sí, unas muchachas de Uruapan nos conta- } \\
\text { ron que tenían una fabriquita de puras } \\
\text { mujeres, pero aquí no se da eso, todas } \\
\text { tienen puños de quehaceres en sus casas } \\
\text { como para pensar en eso. }\end{array}$ & $\begin{array}{l}\text { De reconocimiento } \\
\text { de otras mujeres. }\end{array}$ & \\
\hline $\begin{array}{l}\text { Logística de } \\
\text { mercancías. }\end{array}$ & $\begin{array}{l}\text { Está bien difícil, hay que tener camioneta } \\
\text { y luego tener mucho cuidado, al compadre } \\
\text { Filemón lo vieron con una camioneta } \\
\text { cargada de aguacate, y luego luego que le } \\
\text { cae la maña } a^{4} \text { y le andaban robando hasta } \\
\text { la camioneta. }\end{array}$ & $\begin{array}{l}\text { De denuncia de } \\
\text { violencia en zona. }\end{array}$ & \multirow[t]{3}{*}{ Violencia. } \\
\hline $\begin{array}{l}\text { Mercados loca- } \\
\text { les para aceite de } \\
\text { palta. }\end{array}$ & $\begin{array}{l}\text { Yo invité a mis hermanas para contarles } \\
\text { lo de cocinar con aceite de aguacate, mi } \\
\text { marido me dijo "estás loca" pero, me valió } \\
\text { y de todos modos hicimos carne frita en } \\
\text { aceite de aguacate. }\end{array}$ & $\begin{array}{l}\text { De evidencia de } \\
\text { microviolencia do- } \\
\text { méstica a través de } \\
\text { descalificaciones. }\end{array}$ & \\
\hline $\begin{array}{l}\text { Aplicaciones } \\
\text { cosméticas de la } \\
\text { palta. }\end{array}$ & $\begin{array}{l}\text { Sí convencí a la muchacha aquella que les } \\
\text { platiqué, la que traía moretones por los ca- } \\
\text { rajazos }{ }^{5} \text { de su marido, le dije que se pusiera } \\
\text { una mascarilla de aguacate y sí como que } \\
\text { se le quitó más rápido el moretón. }\end{array}$ & $\begin{array}{l}\text { De denuncia de } \\
\text { violencia domés- } \\
\text { tica. }\end{array}$ & \\
\hline
\end{tabular}

3 "Disque" es un adjetivo coloquial que asume duda o falsedad sobre la legalidad el título, en este contexto un sinónimo podría ser "pseudo ingeniero".

4 La maña es una forma coloquial de nombrar al crimen organizado en diferentes zonas de México.

5 "Carajazo" es una variante dialectal del área rural para nombrar los golpes. 


\begin{tabular}{|c|c|c|c|}
\hline $\begin{array}{l}\text { Conservas de } \\
\text { aguacate. }\end{array}$ & $\begin{array}{l}\text { Estaba haciendo el guacamole y que me } \\
\text { dice mi hijo "hasta crees que va haber un } \\
\text { tarugo que pague por guacamole viejo } \\
\text { enlatado". }\end{array}$ & $\begin{array}{l}\text { De evidencia de } \\
\text { microviolencia do- } \\
\text { méstica a través de } \\
\text { descalificaciones. }\end{array}$ & \\
\hline $\begin{array}{l}\text { Estimación de } \\
\text { porciones. }\end{array}$ & $\begin{array}{l}\text { Pues deberías de aprovechar ahorita que } \\
\text { los chiquillos están viendo las clases en la } \\
\text { televisión, al final es una la que tiene que } \\
\text { poner atención pa saber cómo va a estar la } \\
\text { tarea jeje. [Ríe ante el comentario] }\end{array}$ & $\begin{array}{l}\text { De evidencia de la } \\
\text { nueva realidad por } \\
\text { la pandemia. }\end{array}$ & \multirow[t]{2}{*}{$\begin{array}{l}\text { Pandemia } \\
\text { COVID-19. }\end{array}$} \\
\hline $\begin{array}{l}\text { Polinización de } \\
\text { la palta. }\end{array}$ & $\begin{array}{l}\text { No le hace que ahorita no le entienda, al } \\
\text { rato busco el libro ese de la secundaria, al } \\
\text { cabo dicen que todos los libros de la escuela } \\
\text { ya se pueden ver en el internet. }\end{array}$ & $\begin{array}{l}\text { De evidencia de } \\
\text { oportunidades de } \\
\text { acceso a la infor- } \\
\text { mación. }\end{array}$ & \\
\hline
\end{tabular}

Fuente: Elaboración propia.

A continuación, en la Tabla 2 se presenta un extracto de una de las autobiografías que parecen más ilustrativas en cuanto a dar relato y evidencia a la experiencia de la mujer productora, en la cual se puede apreciar la relación de sus enunciaciones con las categorías que constituyen puestas en común en el resto de las mujeres participantes, y que permiten establecer referencias con el escenario de la región en cuanto a las condiciones que vive la mujer rural. Las condiciones biográficas corresponden a una mujer de origen indígena, con 34 años de edad y a cargo de cuidados de cuatro hijos, su marido y su suegra.

Tabla 2

Entrevista autobiográfica con mujer productora de palta

\begin{tabular}{|c|c|}
\hline Conversaciones & $\begin{array}{l}\text { Relaciones } \\
\text { identificadas }\end{array}$ \\
\hline $\begin{array}{l}\text { ¿Y entonces cómo te viniste de tu pueblo? } \\
\text { O sea que, a mi marido le ofreció trabajo su patrón acá, que } \\
\text { porque acá iban a empezar a plantar una huerta nueva y } \\
\text { necesitaba gente que le supiera, y como mi marido toda la } \\
\text { vida se ha dedicado al aguacate, desde que su papá le enseñó } \\
\text { allá en las huertas de Uruapan, pues entonces agarramos } \\
\text { nuestros chiquillos y con todo y suegra nos venimos pa acá. } \\
\text { El más grandecito apenas estaba de cuatro años y yo todavía } \\
\text { estaba chamaca }{ }^{6} \text {, así que ni le pensé. }\end{array}$ & $\begin{array}{l}\text { Evidencia de un } \\
\text { desplazamiento } \\
\text { por oportunidad } \\
\text { laboral para el varón } \\
\text { que se convierte en } \\
\text { condición para la } \\
\text { mujer. }\end{array}$ \\
\hline
\end{tabular}

6 "Chamaca" es una forma de nombrar a una mujer joven, pero en la mayoría de los casos acusando inexperiencia por su juventud. 
¿Cuántos años tenías?

Apenas tendría los 19 yo creo...

¿A los cuantos años te casaste?

Estaba yo muchachilla, allá la gente se casa bien chiquilla, yo apenas había cumplido los 15 años cuando me casé y luego luego encargamos al primer niño, pero así se acostumbraba allá. Además con tal de salirme de mi casa no me importaba que tuviéramos que vivir de rancho en rancho.

¿Por qué te querías salir de tu casa?

Mi papá tomaba mucho, y le pegaba a mi mamá, y luego teníamos que andarlo cuidando cuando estaba tomado, aquello era una joda ${ }^{7}$. Yo les dije a mis hermanas, ahi se quedan si quieren, yo ya me voy, y la verdad es que me fui primero con el novio y luego ya me casé [sonríe al recordar la escena]

¿Cómo aprendiste a trabajar el aguacate [palta]?

Pues mi marido siempre se ha dedicado a eso, y cuando compramos el terrenito aquí, fue lo primero que se le ocurrió sembrar, él se iba a trabajar a la huerta de Don --- ----- y yo me quedaba cuidando nuestras matas aquí con los chiquillos, y así poco a poquito. Antes era más fácil, ahorita ya se queda y se desperdicia mucho, dice mi marido que porque hay mucha competencia.

¿Cómo haces para cuidar la cosecha y a tus hijos?

Los chiquillos la siguen a una a cualquier cosa que esté haciendo, asi que se vienen conmigo y ahi los entretengo, los más grandes se iban a la escuela y ya me quedaba con los chiquillos. Lo que sí ha sido más delicado es cuidar a mi suegra, porque ya está de edad y necesita mucho cuidado.

¿Cómo les ha ido con las ventas?

Antes era mejor, ahorita está bien fregada la cosa, ya van tres años que no sacamos ni lo del abono, es que ya hay muchos señores en este negocio y las empacadoras casi casi quieren que les regalemos la cosecha. Mi marido me decía que la fuera a vender al mercado de los sábados en Morelia, pero no, es una joda porque hay que ir cargando con chiquillos y todo.

¿Han recibido apoyos de parte de alguna instancia para los pequeños productores?

¿Del gobierno?

¿O de cualquier otra asociación?

No, ya ni nos arrimamos, una vez fuimos que porque iban a dar apoyos y que nos dicen que cuantas hectáreas decía la escritura de nuestra huerta, y le dijimos que como dos y media, y que nos dicen "entonces no se puede porque esto es para propietarios de cinco pa arriba". Les dije "si tuviera cinco ni les venía a pedir" jeje [ríe con sarcasmo].
Evidencia de un sistema patriarcal avalado por las tradiciones.

Denuncia de violencia intrafamiliar.

Evidencia de la responsabilidad de los cuidados desde una mirada patriarcal.
Evidencia de la responsabilidad de los cuidados desde una mirada patriarcal.

\section{Denuncia de} condiciones desventaja entre productores y productoras.

\author{
Denuncia de la \\ inequidad con la que \\ se operan los apoyos \\ agrarios.
}




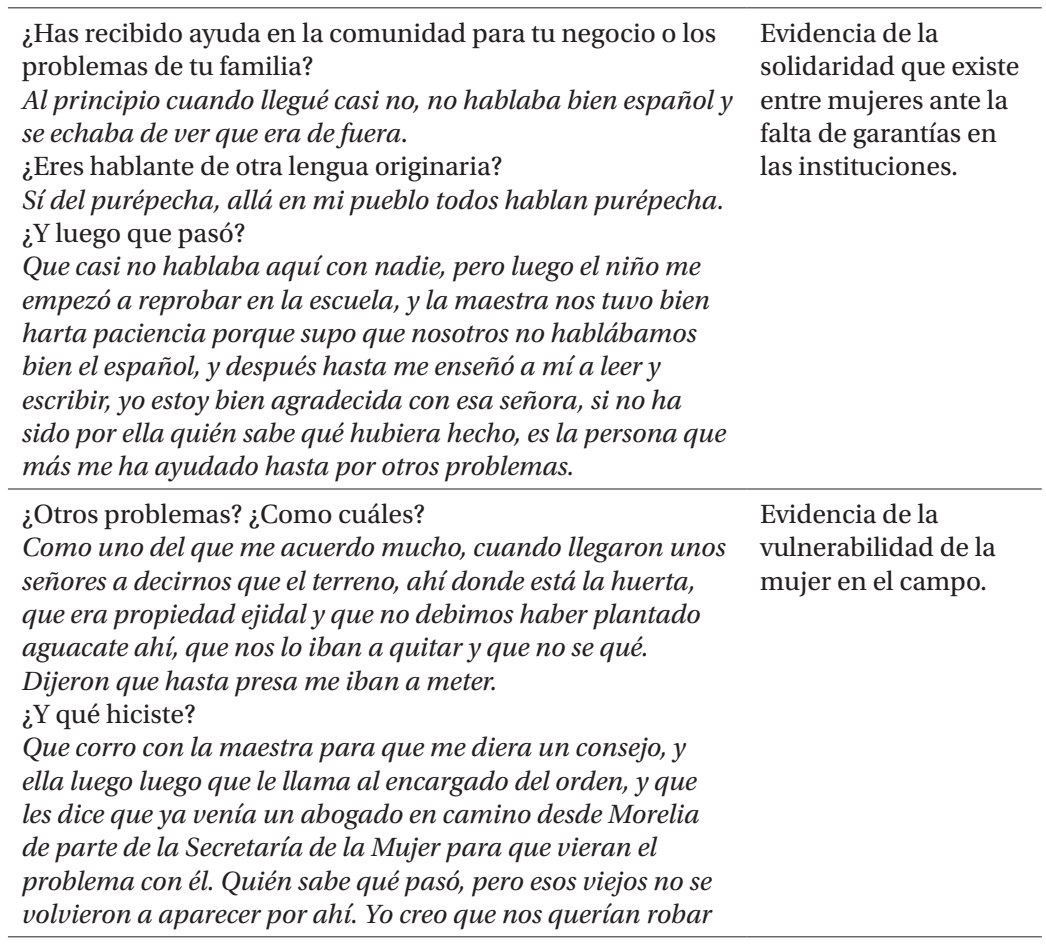

Fuente: Elaboración propia.

A lo largo de todas las entrevistas y grupos de discusión sesionados con las mujeres participantes se incluyeron preguntas explícitas acerca de su sentir ante ciertas circunstancias de la realidad cotidiana. De cada una de las intervenciones se aislaron esos extractos que hacían referencia a una condición concreta para analizar la forma en la que se le enuncia ese sentir ante el contexto inmediato. Entre las más sobresalientes se enlistan a manera de ejemplo las de la Tabla 3, que concentra respuestas aleatorias de todas las participantes.

Tabla 3

Condiciones y emociones de las mujeres productoras de palta

\begin{tabular}{lll}
\hline Cuestionamiento & Respuesta & $\begin{array}{l}\text { Relación de las } \\
\text { emociones }\end{array}$ \\
\hline $\begin{array}{l}\text { ¿Cómo te sentiste } \\
\text { ese día cuando se les } \\
\text { quedó la cosecha? }\end{array}$ & $\begin{array}{l}\text { Bien encanijada la verdad, } \\
\text { con ganas de tener camiones y } \\
\text { yo misma llevarla a vender a } \\
\text { la empacadora de Uruapan y } \\
\text { no andar mendigando con los } \\
\text { canijos intermediarios. }\end{array}$ & $\begin{array}{l}\text { Se manifiesta } \\
\text { frustración ante } \\
\text { competencia }\end{array}$ \\
& inequitativa. \\
\hline
\end{tabular}




\begin{tabular}{|c|c|c|}
\hline $\begin{array}{l}\text { ¿Qué pensabas cuando } \\
\text { la promotora de la feria } \\
\text { los invitaba a poner un } \\
\text { puesto? }\end{array}$ & $\begin{array}{l}\text { Yo me hacía bien hartas } \\
\text { ilusiones, me imaginaba como } \\
\text { si tuviéramos nuestra propia } \\
\text { tienda de aguacate en Morelia. }\end{array}$ & $\begin{array}{l}\text { Se reconoce un } \\
\text { sentido de crecimiento } \\
\text { e independencia } \\
\text { económica. Se enuncia } \\
\text { con ilusión. }\end{array}$ \\
\hline $\begin{array}{l}\text { ¿Qué pensaste cuando } \\
\text { supiste que se podían } \\
\text { hacer todas estas cosas } \\
\text { derivadas de aguacate? }\end{array}$ & $\begin{array}{l}\text { Pensaba que me gustaría } \\
\text { sacarme la lotería para comprar } \\
\text { un buen terreno y fábricas en } \\
\text { las que se pudiera recibir todo } \\
\text { el aguacate que se queda en las } \\
\text { rancherías y convertirlo en todas } \\
\text { esas cosas. }\end{array}$ & $\begin{array}{l}\text { Se manifiesta una } \\
\text { necesidad de inversión } \\
\text { en infraestructura } \\
\text { fuera del alcance } \\
\text { de las familias. Se } \\
\text { da evidencia de } \\
\text { frustración. }\end{array}$ \\
\hline $\begin{array}{l}\text { ¿Te gustaría que tus } \\
\text { hijas se dedicaran a las } \\
\text { matas de aguacate? }\end{array}$ & $\begin{array}{l}\text { No, ellas mejor que estudien y } \\
\text { que se vayan a otro lugar, como } \\
\text { Morelia o Querétaro para que } \\
\text { encuentren un buen trabajo y } \\
\text { no se tengan que romper el lomo } \\
\text { como nosotras. }\end{array}$ & $\begin{array}{l}\text { Se desea una realidad } \\
\text { diferente por desear lo } \\
\text { mejor para sus hijas. Se } \\
\text { enuncia con ilusión. }\end{array}$ \\
\hline $\begin{array}{l}\text { ¿Qué te gustaría que } \\
\text { tus hijas estudiaran? }\end{array}$ & $\begin{array}{l}\text { Así como la maestra que venía } \\
\text { a enseñarnos los experimentos, } \\
\text { esa muchacha se ve que sabe } \\
\text { hartisísimo, además de que } \\
\text { llega en su carro y anda libre } \\
\text { por la vida para arriba y para } \\
\text { abajo. }\end{array}$ & $\begin{array}{l}\text { Se reconoce en la } \\
\text { educación una variable } \\
\text { de mejora para la } \\
\text { vida de las mujeres } \\
\text { que acceden a ella. Se } \\
\text { enuncia con ilusión. }\end{array}$ \\
\hline $\begin{array}{l}\text { ¿Recuerdas tu } \\
\text { comunidad indígena? } \\
\text { ¿La extrañas? }\end{array}$ & $\begin{array}{l}\text { Solamente extraño algunas } \\
\text { cosas, como las fiestas y la } \\
\text { comida, pero lo demás no, la } \\
\text { vida es bien difícil allá, aquí por } \\
\text { lo menos está cerca Morelia y } \\
\text { las tiendas, allá en la sierra no } \\
\text { hay nada. }\end{array}$ & $\begin{array}{l}\text { Se reconoce con tristeza } \\
\text { una realidad precaria } \\
\text { en las comunidades } \\
\text { indígenas. }\end{array}$ \\
\hline $\begin{array}{l}\text { ¿Qué le dirías a los } \\
\text { gobernantes que } \\
\text { deciden sobre los } \\
\text { apoyos al campo? }\end{array}$ & $\begin{array}{l}\text { Que no solamente venga a } \\
\text { asomar la nariz cuando quieren } \\
\text { votos. Y que no les den nomás } \\
\text { dinero a las empacadoras, ellos } \\
\text { ya no lo necesitan, se necesita } \\
\text { aquí para los que chaponeamos }{ }^{8} \\
\text { todavía con azadón. }\end{array}$ & $\begin{array}{l}\text { Se manifiesta coraje } \\
\text { ante una situación de } \\
\text { inequidad propiciada } \\
\text { por las autoridades de } \\
\text { gobierno. }\end{array}$ \\
\hline $\begin{array}{l}\text { Si tuvieras oportunidad } \\
\text { de empezar de nuevo } \\
\text { ¿volverías a sembrar } \\
\text { matas de aguacate en } \\
\text { tu terreno? }\end{array}$ & $\begin{array}{l}\text { La verdad es que no, buscaría } \\
\text { mejor otra cosa, los aguacates } \\
\text { son una joda y ya no es negocio, } \\
\text { solamente es negocio para los } \\
\text { que pelan el monte y plantan } \\
\text { huertas de } 20 \text { o } 30 \text { hectáreas, } \\
\text { así, para una familia con pocas } \\
\text { matas es puro perderle. }\end{array}$ & $\begin{array}{l}\text { Se reconoce con tristeza } \\
\text { una toma de decisiones } \\
\text { que no han dado los } \\
\text { mejores resultados para } \\
\text { ella y su familia. }\end{array}$ \\
\hline
\end{tabular}

Fuente: Elaboración propia.

8 Término coloquial que se refiere a desbrozar o limpiar el terreno de la maleza. 


\section{Discusión y conclusiones}

Como resultado de esta etapa metodológica, trabajada bajo la modalidad de Comunidad de Práctica y Aprendizaje, CAP, que recuperó los diálogos para matizar las experiencias de las propias mujeres productoras de palta, se tienen las siguientes inferencias que son parte de una reconstrucción de la apreciación de la realidad desde la mirada de las mujeres involucradas, y que son acordes con el marco teórico propuesto. Dichas inferencias se integran también con la finalidad de generar nuevas indagatorias que, a su vez, permitan reconstruir las dinámicas de interacción social para con este sector rural, el que pocas veces se incluye en los estudios relacionados con las agroindustrias de América Latina.

Las mujeres productoras de palta reconocen en la operación de políticas públicas un sesgo que las deja fuera de la participación como beneficiarias en un sentido de doble discriminación: en primer lugar, al identificar que por ser pequeñas propietarias no son beneficiadas por las reglas de operación de la agroindustria; y en segundo término, al reconocer que es un espacio pensado para la participación de los varones, debido a la falta de garantías que hay en la región para el ejercicio empresarial independiente de la mujer. Estas condiciones de inequidad coinciden con las ya señaladas por Jarquín et al. (2017), quienes hacen un urgente llamado a la incorporación de miradas interdisciplinarias, principalmente las de la sociología y la antropología para el debate de las políticas públicas a favor de las unidades familiares de producción rural.

Las desigualdades para el desarrollo de la mujer en el trabajo del campo, específicamente en la producción de palta en Michoacán, México, son grandes y multivariadas debido a las condiciones de la pequeña producción y a la discriminación en diferentes sentidos. Dichas desigualdades se multiplican cuando la condición de mujeres se combina con ser indígena, ya que de acuerdo con López y Rojas (2017) "en estos sectores sociales persisten marcadas expresiones de la desigualdad de género y de clase, sustentadas en una estricta división de roles entre hombres y mujeres" (p. 317); dicho señalamiento es reforzado por la experiencia relatada de las mujeres participantes en este estudio. 
En la cotidianidad de las mujeres productoras de palta se aprecia un orden de relaciones patriarcales dictado por la dinámica cotidiana desde la familia. En concordancia con Mora et al. (2017), se identifica que las condiciones de la estructura patriarcal en la familia rural de México segrega a la mujer de varias prerrogativas como ciudadana, por ejemplo: el derecho a la tierra, la participación en la toma de decisiones, la gestión de apoyos como titular ante instancias gubernamentales y el derecho a la educación, entre otras. No obstante, las condiciones de resiliencia que presentan estas mujeres son una característica reconocida entre ellas mismas tras la superación de diferentes adversidades, incluso aquellas que están relacionadas con episodios de violencia y desplazamientos producto de los escenarios hostiles que se viven en el México contemporáneo. Esta condición coincide con otros relatados en Latinoamérica como los que exponen Albarracín y Contreras (2017) dando evidencia de mujeres objeto de violencia por los conflictos armados de Colombia, y sus condiciones para retomar la vida cotidiana en un cambio de paradigma.

A pesar de enfrentar enormes adversidades en sus vidas, las mujeres productoras de palta reconocen un fuerte apoyo en la figura de otras mujeres en quienes, con mayor o menor organización, encuentran acompañamiento para la continuidad de sus dinámicas de vida y recuperar la fortaleza de sus iniciativas. Relatos como los de Robinson et al. (2019), refuerzan este punto de vista mediante la revisión del modelo de colectivos de microempresas conformadas por mujeres, algunas de ellas en comunidades indígenas, igualmente coinciden con los resultados de esta investigación en su señalamiento de que las mujeres productoras encuentran mayor fortaleza en otras mujeres, más que en los espacios institucionalizados por el Estado. En este mismo orden de ideas, las mujeres del campo que otorgan su relato señalan que no desean el tipo de vida que ellas llevan para sus hijas, ya que se reconocen condiciones de opresión y desventaja en comparación con las condiciones de otras mujeres en las zonas urbanas. Así, estas mujeres refuerzan los hallazgos de Rodó (2020), quien a través de un estudio comparativo señala las divergencias del desarrollo de las mujeres rurales en México y en Chile, concluyendo que la condición de ruralidad representa una desventaja en el desarrollo para la niña y adolescente residente de las zonas rurales en estos países. 
Como resultado a destacar, es preponderante el alto nivel de conciencia ecológica y ecosustentable que saben identificar las mujeres productoras de palta en Michocán, México, y es que las mujeres participantes en la CPA manifiestan una fuerte preocupación por la preservación de los recursos naturales, pues saben que es patrimonio de las nuevas generaciones de su familia. Al respecto, incluso reconocen como un modelo posible el negocio ecosustentable desarrollado por mujeres en diferentes regiones de Europa en las que se mezclan las actividades agrícolas, ganaderas y turísticas de una manera respetuosa con el medio ambiente. Al cierre de la CPA, las mujeres reconocen como ideal seguir los ejemplos expuestos por Esteban et al. (2018), donde las españolas de áreas rurales trabajan la explotación ecosustentable de sus recursos naturales a través de la figura de cooperativas de mujeres.

En este orden de ideas, a manera de cierre, se tiene que las mujeres rurales productoras de palta en Michoacán, México, se reconocen en situación de adversidad y en constante resistencia, al tiempo que reconocen con claridad sus necesidades de empoderamiento y promueven la organización de mujeres rurales a favor de una producción sustentable, ética y con equidad de condiciones para su desarrollo en el mercado agrícola. Dichas mujeres se documentan y revisan casos como los expuestos por Soto et al. (2020), en los que se da evidencia de una mirada feminista en la gestión de cooperativas de producción rural en el Estado de Hidalgo y, al mismo tiempo, denuncian una discriminación en contra de la mujer que se hace presente en las diferentes estructuras sociales informales e institucionales, y hasta en las legislativas, que incluso vulneran los derechos humanos, lo que coincide con análisis como los de Martínez et al. (2020) cuando afirman tajantemente que en el Sistema de Justicia Mexicano no se puede garantizar la justicia para la mujer en términos de igualdad.

Al cierre de estas líneas se concluye que, instituciones, asociaciones y autoridades, pero sobre todo otras mujeres, se encuentran concentrando esfuerzos a favor de un cambio en el paradigma de la mujer productora de palta en México, una transformación en la que se privilegien sus garantías individuales, sus aspiraciones como empresarias independientes, sus derechos de libre mercado en igualdad de condiciones y su bienestar emocional para ellas y sus familias, en un entorno en el que a todas luces se ha evidenciado como adverso. 


\section{Referencias}

Albarracín. A. y Contreras, K. (2017). La fuerza de las mujeres: un estudio de las estrategias de resiliencia y la transformación en la ocupación humana de mujeres víctimas del conflicto armado en Colombia. Revista Ocupación Humana, 17(1), 25-38. https://doi.org/10.25214/25907816.154

Arias F. y Arboleda O. (2018). Dinámica del mercado mundial de aguacate. Revista Virtual Universidad Católica del Norte, 55(1), 22-35. http://dx.doi.org/10.35575/rvucn.n55a2

Arriagada, E. y Zambra, A. (2019). Apuntes iniciales para la construcción de una ecología política feminista de y desde Latinoamérica. Polis (Santiago), 18(54), 14-38. https://dx.doi. org/10.32735/s0718-6568/2019-n54-1399

Caballero, B., Finglas, P., y Toldrá, F. (2015). Encyclopedia of food and health. Waltham, Elsevier.

Casparello, G. (2018). Análisis del conflicto y de la violencia en Cherán, Michoacán. Relaciones Estudios de Historia y Sociedad, 155(1), 77-112. http://dx.doi.org/10.24901/rehs.v39i155.289

Centro de Estudios para el Desarrollo Rural Sustentable y la Soberanía Alimentaria, CEDRSSA. (2017). Reporte, caso de exportación: el aguacate. [Archivo PDF]. http://www.cedrssa.gob.mx/ files/b/13/54Exportaci\%C3\%B3n\%20aguacate.pdf

Díaz, R. (2011). El taller del etnógrafo: Materiales y herramientas de investigación en etnografía. Universidad Nacional de Educación a Distancia, UNED.

Esteban, M., Pérez, F., y Gargallo Castel A. (2018). Áreas rurales y cooperativas: iniciativas de mujeres para el desarrollo. Revesco: Revista de Estudios Cooperativos, (127), 116-138. http:// dx.doi.org/10.5209/REVE.58397

Farías, A. (2020). Diabetes: comunicación, discriminación y dominación en mujeres rurales de Michoacán. En M. Petracci y J. García (Coords.), Comunicación y salud en América Latina: contribuciones al campo (pp. 15-26). Universidad Autónoma de Barcelona. https://ddd.uab.cat/record/233410

Galindo, J. (1998). Técnicas de investigación en sociedad, cultura y comunicación. Pearson Educación.

Herrera, E. (2017). Oro verde a la sombra del volcán: La agroindustria transnacional del aguacate y las transformaciones 
de tenencia de la tierra en la Meseta P'urhépecha [Tesis de doctorado]. https://colmich.repositorioinstitucional. $\mathrm{mx} /$ jspui/bitstream/1016/197/1/HerreraAguilarEunice2017Tesis.pdf

Jarquín, N., Castellanos, J., y Sangerman, D. (2017). Pluriactividad y agricultura familiar: retos del desarrollo rural en México. Revista Mexicana de Ciencias Agrícolas, 8(4), 949-963. https:// doi.org/10.29312/remexca.v8i4.19

López, V. y Rojas, O. (2017). Rezagos en el nivel de autonomía de las mujeres rurales mexicanas en la primera década del siglo XXI. Estudios Demográficos y Urbanos, 32(2), 315-354. https://doi.org/10.24201/edu.v32i2.1644

Maldonado, S. (2019). Los retos de la seguridad en Michoacán. Revista Mexicana de Sociología, 81(4), 737-763. https://doi. org/10.22201/iis.01882503p.2019.4.57977

Martínez, I., Mendoza, L., y Mamani, S. (2020). Vulneración sistemática de los derechos humanos de las mujeres en el estado patriarcal mexicano: caso Yakiri Rubí Rubio. Revista Direitos Humanos e Sociedade, 2(2), 1-18. http://periodicos.unesc.net/ dirhumanos

Mora, J., Martínez, M., Jaramillo, J., y Chávez, M. (2017). Participación en el sector no agropecuario en el México rural: una perspectiva de género. Revista Brasileira de Estudos de População, 34(2), 367-389. http://dx.doi.org/10.20947/S0102-3098a0020

Nightingale, A. (2006). The nature of gender: Work, gender, and environment. Environment and Planning D: Society and Space, 24(2), 165-185. https://doi.org/10.1068/d01k

Organización para la Cooperación y el Desarrollo Económicos, OCDEOrganización de las Naciones Unidas para la Alimentación y la Agricultura, FAO (2019). Perspectivas Agrícolas 2019-2028. https://doi.org/10.1787/7b2e8ba3-es

Robinson, D., Díaz, I., y Cruz, S. (2019). Empoderamiento de la mujer rural e indígena en México a través de grupos productivos y microempresas sociales. RETOS. Revista de Ciencias de la Administración y Economía, 9(17), 91-108. http://dx.doi. org/10.17163/ret.n17.2019.06

Robles, H. (2016). La pequeña agricultura campesina y familiar: construyendo una propuesta desde la sociedad. EntreDiversidades, (7), 46-83. https://doi.org/10.31644/ED.7.2016.a02 
Rodó, F. (2020). Divergencias en la feminización del campo: un análisis interseccional de las mujeres rurales en México y Chile. Estudios Rurales, 10(20). http://portal.amelica.org/ameli/ jatsRepo/181/1811302015/index.html

Soto, J. (2019). Alternativas al desarrollo: cooperativa de mujeres indígenas. Política y Cultura, (52), 171-189. https://polcul.xoc. uam.mx/index.php/polcul/article/view/1412/1364

Soto, J., Gómez, D., Juárez, E., y Rojas, A. (2020). La ecología política feminista y cooperativas dirigidas por mujeres rurales en Hidalgo, México. Textual, (75), 131-155. https://doi. org/10.5154/r.textual.2020.75.06

Toribio, M., Ramírez, C., y Núñez, M. (2019). Expansión del agronegocio aguacatero sobre los territorios campesinos en Michoacán. Eutopía. Revista de Desarrollo Económico Territorial, (16), 51-72. https://doi.org/10.17141/eutopia.16.2019.4117

Vázquez, V. (2020). Género y privatización del ejido en San Salvador Atenco, México. Perfiles latinoamericanos, 28(55), 325-348. https://doi.org/10.18504/pl2855-013-2020

Wenger, E. y Sánchez, B. (2001). Comunidades de práctica: aprendizaje, significado e identidad. Paidós. 